\title{
Inclusão indígena e exclusão dos afro-descendentes na América Latina*
}

Juliet Hooker

Tradução de Alexandre Massella

Introdução

A América Latina apresenta um al to grau de desigualdade racial e de discriminação contra populações afro-descendentes e indígenas. Isso é verdade a despeito das medidas constitucionais e estatutárias que proíbem a discriminação racial na maioria dos países da região. N as décadas de 1980 e 1990, além da proscrição legal do racismo, vários países latino-americanos implementaram reformas visando à cidadania multicultural, as quais estabeleceram al guns direitos coletivos para os grupos indígenas. M as em relação aos afro-descendentes não ocorreu o mesmo. 0 s direitos coletivos obtidos com essas reformas incluem: reconhecimento formal de subgrupos étnicos ou raciais específicos e da natureza multicultural das sociedades nacionais; reconhecimento do direito consuetudinário como direito público oficial; direitos de propriedade coletiva (especialmente em relação à terra); status oficial para a língua deminorias em regiõesem queestas predominam; egarantia de educação bilíngüe. Argentina, Bolívia, Brasil, Chile, Colômbia, Costa Rica, Equador, Guatemala, H onduras, M éxico, N icarágua, Panamá, Paraguai, Peru e Venezuela asseguraram pelo menos um e, em muitos casos, todos esses direitos coletivos no direito constitucional ou estatutário. Além disso, todos esses países, com exceção de C hile, N icarágua e Panamá, ratificaram a Convenção 169 da O rganização Internacional do Trabalho

* Este artigo foi originalmentepublicadoem inglês no Journal of Latin American Studies A pesquisa foi financiada pelo Programa Rockefeller sobre Raça, Direitos e Recursos nas Américas, daU niversidadedo Texas. Agradeço, peloscomentáriose sugestões úteis, a H enry Dietz, Edmund T. Gordon, LarryGraham, Ken Greene, CharlesR. $\mathrm{H}$ ale, Wendy H unter, Raúl M adrid, John Sides, Eva Thorne, João Vargas, Kurt Weyland e quatro resenhistas anônimos do JLAS.

1.Donna Lee Van Cott (2000a) identifica esses direitos como os 
cinco elementos do queela chama de "modelo multicultural".

2.Ver, por exemplo, Van Cott (2000b) e Yashar (1999).

3. No Brasil, as comunidades rurais de descendentesdeescravosforagidos, conhecidas como quilombos, têm direitos comunais sobre a terra. $\mathrm{NaC}$ olômbia, as comunidades negras ribeirinhasdacostado Paćíico eosraizaisdelínguainglesa (população queocupa 0 arquipélago de San Andrés, Providencia e Santa Catalina, posses são colombiana situada uns duzentos quilômetrosalestedaN icarágua) conquistaram direitoscoletivosàterraeànreserva çãodesuasculturastradicionais com a Lè 70, de 1993, que, em prinćpio, estendiataisdiretospara além dacostado Paćíico, já queseus artigosfazem referênciaatodososafrocolombianosegarantem osdireitosàterradascomunidades negras que vivem em circunstâncias similares àquelas da região do Paćficico. A Constituição equatoriana de 1998 reconheceaos afroequatorianos os seguintes direitos concedidos aos povosindígenas, "na medida em que sejam
(O IT ) sobreos D ireitos dos Povos I ndígenas eTribais. As reformas da cidadania multicultural foram interpretadas como tentativas de restabelecer, mediante a inclusão de minorias étnicas e raciais antes excluídas ea reparação do antigo racismo, a legitimidade democrática do Estado, após décadas de autoritarismo e repressão em alguns países².

Entretanto, há disparidades significativas no escopo dos direitos coletivos contemplados por tais reformas. Em quase todos os casos de reforma multicultural na América Latina, os grupos indígenas foram muito mais bem-sucedidos na obtenção desses direitos do que os afro-descendentes. D os quinze países latino-americanos que implementaram al gum tipo de reforma visando à cidadania multicultural, somente Brasil, Colômbia, Equador, G uatemala, $\mathrm{H}$ onduras e N icarágua estenderam al guns direitos coletivos aos afro-descendentes ${ }^{3}$. M as mesmo nos casos em que obtiveram esses direitos, em quase nenhum país os afro-descendentes foram contemplados da mesma maneira que povos indígenas. D e fato, em apenas três países da região - H onduras, Guatemala eN icarágua - indígenas eafro-descendentes têm direitos coletivos iguais. Além disso, apenas um pequeno subconjunto de afro-descendentes - em geral comunidades rurais que descendem de escravosforagidos- conquistou direitos coletivos duranteas mencionadas reformas. A pesar dea grande maioria dos afro-descendentes estar excluída das recentes reformas que asseguraram direitos coletivos, somente o Brasil ea Colômbia estão tentando elaborar outros meios legais para combater o racismo, como a legislação relativa aos direitoscivis. Esteartigo procura explicar o escopo desigual dosnovos regimes decidadania multicultural da Amé rica Latina e apontar suas conseqüências. Abordaremos duas questões, distintas mas relacionadas. Em primeiro lugar, por quenaAmérica Latina os afro-descendentes obtiveram menos direitos coletivos com essas reformas do que os povos indígenas? Em segundo, dado o escopo desigual, até que ponto os novos regimes de cidadania multicultural são eficazes para enfrentar o problema da desigualdade racial?

Indígenas e afro-descendentes constituem uma porcentagem significativa da população total da América Latina, e os dois grupos sofrem exclusão social e discriminação racial. D e fato, na população total da região, a porcentagem de afro-descendentes é maior do que a de indígenas. A C omissão Econômica para a América L atina e o C aribe (C ealc) avalia que há entre 33 e 40 milhões de indígenas na região, o que equivale a cerca de $8 \%$ da população total. 0 número de afro-descendentes estaria, segundo a Cealc, em torno de 150 milhões de pessoas, ou seja, 30\% da população da região (cf. 
H openhayn e Bello, 2001). Embora as estimativas a respeito do tamanho desses grupos na América Latina sejam controversas - em parte porque muitos países da região não incluem questões relativas à raça em seu censo nacional - , não há dúvida de que a quantidade de afro-descendentes épelo menos equivalente à de indígenas4.

O sdoisgrupossão al vos de discriminação racial. Segundo o Banco InterAmericano de D esenvolvimento e a C ealc, ambos são vítimas de "exclusão social", entendida como a impossibilidadedeum grupo social participar ple namente das efferas social, política, cultural e econômica da sociedade (cf. 0 akley, 2001). Em outras palavras, como sugere o título de uma pesquisa, há "custos significativos em não ser branco" na América Latina, custos suportados pelos dois grupos que, de forma desproporcional, são atingidos pela pobreza, a falta de acesso a serviços sociais básicos como saúde e educação, o desemprego ea discriminação no mercado detrabal ho (cf. Silva, 2000, pp. 18-28). N a Guatemala, por exemplo, país em que $66 \%$ da população é pobre, osindígenas são desproporcional mentepobres: $87 \%$ doslaresindígenas viveabai xo da linha de pobreza (cf. Patrinos, 2000, p. 4). N o Brasil, $60 \%$ dos afro-brasil leiros são pobres, ou seja, o dobro da taxa relativa aos brancos (cf. Arias eD uryea, s.d.). Esseíndice desproporcionalmenteal to de pobreza entre os indígenas e os negros latino-americanos reflete o reduzido nível de escolaridadee o menor acesso a serviços sociais básicos observados nos dois grupos. No Panamá, por exemplo, a taxa de analfabetismo é de 3,3\% nas áreas urbanas e de $15 \%$ nasáreas rurais, mas, entreos gruposindígenas, éde $44,3 \%$. 0 s povos indígenas têm ainda menos acesso a serviços de saúde do queas populações não-indígenas. $\mathrm{N}$ a Bolívia, $70 \%$ da população tem acesso a serviços de saúde nos municípios em que a população não-indígena é maioria, ao passo quesomente $11 \%$ se beneficia desses serviços nos municípios de maioria indígena (cf. H openhayn e Bello, 2001, p. 20). O s afrodescendentestambém exibem valores medíocresna maioria dosindicadores socioeconômicos. $\mathrm{NaC}$ olômbia, por exemplo, onde $32 \%$ da população nacional vivena pobreza, $84,87 \%$ doshabitantes da região do Pacífico conhecida como C hocó, que é $90 \%$ afro-colombiana, é pobre. A taxa nacional de analfabetismo é de $11 \%$, mas sobe para $38,3 \%$ no C hocó, onde $41 \%$ dos lares carece de saneamento básico, contra apenas $10 \%$ em âmbito nacional (cf. 0 akley, 2001, pp. 24-25). 0 safro-descendentestambém sofrem discriminação racial no mercado detrabal ho, já que, em qual quer nível educacional, eles tendem a ganhar menos do que os brancos. No Brasil, o único país para o qual dispomos de dados confiáveis, a renda dos negros, isto é, das aplicáveis": direito a de senvolver e fortalecer a identidadeespiritual, cultural e as tradições lingüísticas, direito àpropriedade coletiva das terras comunais, direito a opinar sobre a exploração dosrecursosnaturaisencontrados nessasterrase a participar dos benefícios derivados da exploração, direito a conservar suasformas deorganiza ção social e governo eà propriedade intelectual sobre o conhecimento tradicional eà educação bilíngüe. Em H onduras, Guatemalae N icarágua, osafro-descendentestêm osmesmos direitos que osgruposindígenas; em $\mathrm{H}$ onduras e na Guate mala, isso significa direito à propriedade coletiva da terra eà educação bilíngüe e, na N icarágua, todos os elementos do modelo multicultural.

4.0 quecomplica ainda mais as estimativas sobre o tamanho das populações indígena e afro-descendente na América Latinaéo fato de que os mulatos são incluídosnapopulação afro-descendente, ao passo que os mestizos são excluídos da população indígena. 
5. Agradeço a um dos resenhistas do JLAS por chamar minha atenção para essa importantedistinção. Sobre essa questão, ver também Lovell (1994, pp. 7-35).

6.0 exemplo paradigmático é o mito da democracia racial, quenão só retrata os países como constituídos por uma mistura racial que impossibilitaria a distinção entre diferentesgrupos, mastambém nega, portanto, a própria existência do racismo. pessoas quese identificam como "negras ou pretas", é40\% da dosbrancos, e a renda dos "pardos" é 44\% da dos brancos (cf. Silva, 2000, p. 21).

É claro que se poderia argumentar que esses dados a respeito de disparidadessocioeconômicas refletem mais a exclusão histórica do queum processo ativo e presente de discriminação racial. Esse argumento, bem como a afirmação de quea desigual dade racial reflete as disparidades de classe, enão a discriminação racial, é usado para sustentar a tese de que a desigualdade racial na América L atina não resulta do racismo contemporâneo. Vale ressaltar, portanto, que nosso argumento aqui diz respeito à existência de discriminação racial contemporânea e não simplesmente à exclusão histórica de afro-descendenteseindígenas. A pesquisa de $\mathrm{N}$ el son do Vallesobrea disparidade derenda no Brasil, por exemplo, mostra queas diferenças salariaisentre brancose não-brancos persistem mesmo quando se controla variáveis como educação e experiência; defato, essas diferenças tendem a ser maiores quando aumenta a escolaridade ${ }^{5}$. Processos ativos de discriminação racial são, assim, pelo menos em parte, responsáveis pelo alto custo de não ser branco, suportado por indígenas e afro-descendentes na América L atina atual.

D ado que os dois grupos sofrem discriminação racial, um dos aspectos mais enigmáticos das reformas de cidadania cultural adotadas para corrigir tais problemas são as simultâneas inclusão dos indígenas e exclusão dos afro-descendentes. Se os dois grupos sofrem a discriminação racial e a exclusão social, por que os afro-descendentes não foram tão bem-sucedidos quanto os indígenas na conquista de direitos coletivos? Se os afro-descendentes em geral sofrem discriminação racial, por que as pessoas desse grupo que conquistaram tais direitos representam uma pequena porcentagem da população total de descendentes de africanos da região? O s trabalhos dos especialistas em mobilização indígena na A mérica Latina, embora extremamente úteis para entender a inesperada adoção de reformas de cidadania multicultural pelos governos da região, não ajudam tanto na explicação da exclusão dos afro-descendentes.

A recente implementação das reformas de cidadania multicultural na A mérica Latina é surpreendente se levarmos em conta que muitos países da região elaboraram ideologias nacionais de mestiçagem que enfatizavam a mistura racial da população e, assim, a ausência de discriminação racial ou cultural ${ }^{6}$. D essa forma, a mai oria desses países nem sequer reconhecia a existência de populações indígenas e afro-descendentes. U ma explicação para a adoção de políticas culturais nas duas últimas décadas é que as reformas neoliberais, especial mente as políticas de ajuste econômico, puse- 
ram em risco a autonomia local e os meios de vida das populações indígenas, desencadeando, assim, uma crescente mobilização étnica que, por sua vez, forçou os governos latino-americanos a atender às demandas indígenas ${ }^{7}$. O utros sustentam que as elites nacionais adotaram tais reformas como um meio de legitimação interna do Estado, num momento em que este enfrentava dificuldades cada vez maiores para satisfazer as demandas materiais de seus cidadãos (cf. Van Cott, 2000b). Alguns, por fim, sugerem que os Estados neoliberais da América Latina atenderam a certas demandas dos grupos indígenas para deslegitimar reivindicações mais radicais (cf. $\mathrm{H}$ ale, 2002, pp. 485-524). Tais abordagens fornecem explicações convincentes para a proeminência das políticas étnicas na América Latina nas últimas décadas, mas tendem a enfatizar os estímulos e as pressões que levaram os governos latino-americanos a atender as demandas por direitos coletivos feitas pelas minorias e as condições estruturais que induziram esses grupos a se mobilizar em torno de tais direitos. Essas explicações não esclarecem por que os afro-descendentes não conquistaram os mesmos direitos coletivos que os grupos indígenas durante as duas décadas de reformas de cidadania multicultural na região.

O s poucos pesquisadores que notaram a discrepância entre os direitos coletivos conquistados pelos dois grupos sugeriram diversas explicações, como a diferença no contingente populacional, a maior capacidade organizacional do movimento indígena ou a ausência de mobilização política dos afro-descendentes em torno de direitos coletivos. Embora relevantes, esses fatores não explicam aquela discrepância. 0 sautores enfatizaram as diferenças entre as políticas indígenas e afro-descendentes, isto é, os tipos de demandas feitas e a eficácia dos grupos para promovêlas, sem dar atenção suficiente à questão de por que os governos se mostraram mais dispostos a garantir direitos a um grupo do que a outro. Para entender a questão écrucial considerar também por queas elites nacionaisea opinião pública foram mais sensíveis às reivindicações dos grupos indígenas. É possível queo obje tivo das reformas multiculturaisfosse promover a legitimidade democrática remediando a exclusão social, mas os critérios usados para determinar os sujeitos que se beneficiariam dos direitos coletivos não foram a discriminação racial ou a marginalização política esocioeconômica. Argumentarei que o principal critério empregado para determinar os beneficiários foi a posse deumaidentidade cultural degrupo distinta. Além disso, em razão das diferentes maneiras pelas quais os dois grupos foram racializados na América Latina, a utilização de uma identidade de grupo distinta, concebida de for-
7.Ver, por exemplo, Brysk e Wise (1997, pp. 76-105) e Yashar (1999). 
8. Como ocorre com qualquer pesquisacomparativaquetentaanalisar tendências em toda umaregião, hálimitesao número de países que podem ser considerados deformadetalhada. Examino uma variedade de casos da América Central edoSul paramostrar que os padrões identificados são válidos para todaaregião, masospaíses caribenhos não foramincluídosnaanálise. A razão dessa exclusão é que, pelo que sei, esses paísesnão implementaram políticas multiculturais similares às do restantedaAméricaLa tina. O utras pesquisas seriam necessárias para determinar se e em que medida ospaísescaribenhos estão implementando políticasmulticulturaisvoltadasàpopulação negraeindígenaese háou não discrepâncias querefletem aquelasobservadas no restante da América Latina.

9.D eborah Yashar e Donna Lee Van Cott estão entre os poucos pesquisadores que, ao analisar a reforma de cidadania multicultural naAmérica Latina, fornecem razões para pôr de lado os afro-descendentes e enfatizar ape ma étnica ou cultural, como critério para a concessão de direitos coletivos, permitiu que os indígenas fossem mais bem-sucedidos do que os afro-descendentes na reivindicação de tais direitos. É importante compreender as raízes dessa discrepância, poisos direitos col etivos baseadosna diferença cultural se tornaram a principal via legal para reverter a exclusão política e a discriminação racial sofrida pelos dois grupos. As reformas multiculturais contemporâneas constituem, assim, a "estrutura de oportunidade política" que se apresenta aos movimentos indígenas e afro-descendentes da região.

Este artigo é dividido em três partes. A primeira analisa os fatores geralmente mencionados para explicar o diferente nível de êxito dos dois grupos na obtenção de direitos coletivos. Valendo-me de exemplos de toda a região, mostro que não é verdadeira a idéia de que os afro-descendentes não se mobilizaram para conquistar direitos coletivos e que as diferenças no tamanho da população e no nível de organização dos movimentos de ambos os grupos não explicam a variação observada. N a segunda parte, explico por que os Estados nacionais se mostraram mais dispostos a garantir direitos coletivos aos indígenas. C onsidero que o modo diferente pelo qual cada grupo foi historicamente racializado influenciou nas respectivas capacidades de rei vindicar direitos coletivos por meio da diferença cultural, já que os grupos indígenas, ao contrário dos afro-descendentes, são vistos como tendo, e pretendendo ter, uma identidade cultural distinta. A terceira parte, por fim, analisa as conseqüências da atual política étnica e racial latinoamericana, geradas pela circunstância de que os direitos coletivos baseados na diferença cultural se tornaram o centro dos esforços para combater a discriminação racial e a marginalização política sofrida pelos dois grupos; enfatizo, em particular, as conseqüências de uma estratégia de discriminação anti-racial que se aplica apenas a um pequeno subconjunto da população afro-descendente, isto é, aquele que consegue afirmar uma identidade cultural distinta ${ }^{8}$.

A explicação da inclusão indígena e da exclusão dos afro-descendentes

0 maior êxito dos gruposindígenas comparado ao dos afro-descendentes na conquista de direitos coletivos durante as recentes reformas de cidadania multicultural na América Latina recebeu pouca atenção ${ }^{9}$. Q uando 0 fenômeno foi notado, a discrepância foi atribuída, em grande parte, a uma combinação dos seguintes fatores: diferenças no tamanho das populações indígenas e afro-descendentes, falta de mobilização política em torno dos 
direitos coletivos por parte dos afro-descendentes emaior nível de organização nos movimentos indígenas do que nos afro-descendentes.

Argumentou-se, por exemplo, que o tamanho relativo da população indígena eafro-descendente podeser um fator que explica o êxito na conquista de direitos coletivos ${ }^{10}$. A idéia é que os afro-descendentes não obtiveram os mesmos direitos coletivos porque representam uma porcentagem maior da população na maioria dos países latino-americanos, constituindo, assim, um perigo considerável às elites econômicas e políticas. Segundo essa hipótese, caberia esperar que, nos países com grande população afro-descendente e pequena população indígena, esta conquistaria mais direitos coletivos do que aquela, ao passo que nos países em que a situação demográfica fosse inversa os afro-descendentes obteriam mais direitos col etivos do que os indígenas. Todavia, em nenhum país latino-americano os afro-descendentes obtiveram mais direitos coletivos do que os indígenas. N os casos em que as conquistas foram similares, como em H onduras ena $\mathrm{N}$ icarágua, o êxito dos afro-descendentes explica-se pelo fato de el es se apresentarem como grupos "autóctones" com o mesmo status dos indígenas e com identidade cultural distinta, e não pelo interesse que as elites teriam em limitar o tamanho da população autorizada a reivindicar direitos coletivos ${ }^{11}$.

Com efeito, parece não haver correlação entre o tamanho da população ea medida de direitos coletivos conquistados por qual quer minoria na Amé rica Latina. Comparando os países da região quanto ao êxito relativo dos grupos indígenas na conquista de tais direitos, percebemos que não se sustenta a idéia de que os países de grande população indígena concederam menos direitos coletivos do que os de menor. A Bolívia, por exemplo, concedeu muito mais direitos coletivos aos indígenas do queo $\mathrm{C}$ hile, ainda que os indígenas constituam de $50 \%$ a $70 \%$ da população boliviana e somente $10 \%$ da população chilena. Embora o tamanho da população possa ser um fator importante na decisão das elites a respeito dos direitos coletivos, ele não explica a discrepância das conquistas dos dois grupos no interior dos países latino-americanos e entre eles.

Aponta-se ainda a diferença no nível e no tipo de organização dos movimentos dos dois grupos. Assim, os afro-descendentes teriam conquistado menos direitos coletivos porque, comparado aos indígenas, seu menor nível de identificação grupal não gerou suficiente mobilização política em torno do tema ${ }^{12}$. A razão para não incluir os afro-descendentes na análise das reformas em questão seria, portanto, essa menor propensão à organização em favor de uma identidade de grupo distinta e dos direitos nas os movimentos indígenas.

10.Van Cott (2000b) sugere, por exemplo, que os afro-equatorianos ganharam, com a Constituição de 1998, direitos mais amplos do que os afro-colombianos em 1991, em parte porque representam uma porcentagem da população total do Equador muito menor do que a dos afro-coIombianos na Colômbia, o que tornou seus direitos coletivos menosameaçadores às elites. Avalia-se que os afro-descendentes constituam entre $4 \%$ e $22 \%$ da população colombiana (com algumas áreas da costa do Pacífico entre $80 \%$ e 90\%) e cercade $3 \%$ da população equatoriana. Em contraste, de $1 \%$ a $4 \%$ dos colombianos éidentificado como índio, porcentagem que sobe para $25 \%$ no Equador. Como nota mos antes, as estimativas do tamanho da população indígena e afro-descendente na América Latina são controversas. O s dados aqui foram extraídos do CIA World Factbook 2003. A variação dasestimativasdependedain- 
clusão ou não das populaçõesmestiçasnasca tegorias "afro-descendente" e "indígena". Ver http://www.odci.gov/ cia/publications/factbook /index.html.

11. No caso hondurenho, por exemplo, dos nove "povos autóctones" reconhecidospelo Estado, os dois grupos que reivindicam a ascendência africana, os garifuna (250 mil) eos negros de fala inglesa (80 mil), estão em segundo e terceiro lugares no que diz respeito ao tamanho da população, atrás apenas doslenca (400 mil). $0 \mathrm{~s}$ dados populacionais foram extraídos de Anderson (2003).

12.Yashar (1999, p. 104, n. 66), por exemplo, argumenta que a organização política dos afro-descendentes na América Latina se limitou aos movimentos urbanos e que as demandas dos movimentos negros urbanos diferem, de forma significativa, das dos movimentosindígenas rurais; aqueles enfatizam a plena inclusão no sistema, e não os direitos coletivos. Van Cott (2000b, p. 276) correspondentes, circunstância que os teria deixado em segundo plano na política multicultural latino-americana. D e acordo com essa perspectiva, os afro-descendentes não se mobilizaram, na mesma medida que os indígenas, para a luta por direitos coletivos relativos à terra, à autonomia política, à educação bilíngüe ou ao reconhecimento do direito costumeiro e das estruturas de autoridade tradicionais. Considera-se, ainda, que essa distinção de natureza política seria conseqüência de diferenças estruturais entre os dois grupos, por exemplo, predomínio de população rural ou urbana, nível de identificação grupal etc.

H á muito a ser dito em favor dos dois argumentos. A literatura sobre política racial na América Latina tendea enfatizar o reduzido nível de identificação grupal entre os afro-descendentes e o caráter predominantemente urbano de seus movimentos políticos. H á muito tempo a América Latina é considerada uma região com níveis relativamente baixos de identificação racial e étnica entre os afro-descendentes. U ma importante tendência na literatura sobre o tema enfatizou, assim, a explicação dessa ausência de identificação racial grupal entre os afro-descendentes da região quando comparada a outras áreas do mundo com grande população de negros, como os Estados U nidos ${ }^{13}$; enfatizou ainda o papel desempenhado pelas instituições políticas, incluindo estruturas estatais supostamente apolíticas, como as agências censitárias, na constitui ção de padrões de identificação racial entre os afro-descendentes e, portanto, de comportamento político destes ${ }^{14}$. N ão se trata de negar que em muitos países da região os movimentos políticos dosafro-descendentes foram principalmente urbanos ou quetais movimentos tenderam a não se organizar para obter direitos como a propriedade coletiva da terra, ao passo que os indígenas têm uma longa história de luta pela terra ${ }^{15}$. Trata-se, sim, de apontar que, se examinarmos a variedade de movimentos afro-descendentes em toda a América Latina, veremos que há afro-descendentes no campo que se mobilizam para conquistar direitos coletivos para suas comunidades e, assim, é preciso explicar por que eles não foram tão bem-sucedidos quanto os indígenas na obtenção de tais direitos.

Em certos países da região, como Brasil, C olômbia, Equador, $\mathrm{H}$ onduras e N icarágua, populações rurais de afro-descendentes lutaram por direitos à terra comunal, controle sobre recursos naturais, autonomia territorial ou política e reconhecimento cultural. D e fato, os casos em que essas populações ganharam o reconhecimento como grupos distintos com direitos coletivos próprios, em particular os relativos à terra ou à autonomia territorial, foram, em geral, aqueles em que a existência de comunidades rurais de 
descendentes de escravos foragidos possibilitou a articulação das lutas em torno de uma retórica similar à dos povos indígenas. As reivindicações pela terra e outros direitos coletivos formuladas por essas comunidades negras conhecidas como quilombos no Brasil, creoles e garifuna na América C entral e cimarrones ou palenques na Colômbia e no Equador - são similares àquelas apresentadas pelas comunidades indígenas. As análises tradicionais da dinâmica racial na América Latina (e da mobilização indígena) não podem, assim, explicar, como aponta Eva Thorne, por que e em que contextos a identidade negra rural se tornou politizada e como as lutas indígenas contribuíram para esse processo (cf. Thorne, 2003, p. 5). Em vez de enfatizar as diferenças entre a política afro-descendente e a indígena, como propõem as análises da mobilização indígena, é preciso considerar, como sugere $M$ ark Anderson, "por que, na América Latina, a mobilização negra (às vezes) se parece à indígena" e quais as conseqüências desse paralelo para o êxito nas lutas.

A pesar dessa similaridade na iniciativa política, é importante apontar que as comunidades rurais de afro-descendentes que fizeram reivindicações baseadas em uma identidade cultural distinta representam uma pequena parcela da população total de afro-descendentes na América Latina. M as, contrariando a expectativa de que as populações urbanas seriam mais militantes e mobilizadas, parece que o isolamento regional e espacial écapaz de promover um alto grau de identificação grupal - étnica ou racial - entre os afro-descendentese, portanto, a mobilização pelos direitos coletivos. A existência de comunidades rurais de afro-descendentes que reivindicam direitos similares aos dos indígenas sugere a relevância da questão rural/urbano quando se trata da organização em torno dos direitos coletivos. Ao mesmo tempo, porém, se as comunidades de afro-descendentestambém se mobilizaram, então permanece sem resposta o problema de por que a identidade indígena se mostrou mais politizada do que a negra no contexto das reformas multiculturais. Seria preciso explicar por que os governos garantiram, em geral, mais direitos aos indígenas do que aos afro-descendentes, mesmo em países em que existiam comunidades rurais destes últimos.

O s estudiosos da mobilização consideram ainda que o maior êxito comparativo dos grupos indígenas explica-se pelo menor nível de organização dos movimentos afro-descendentes ${ }^{16}$. É difícil contestar o fato de que há uma longa e bem-sucedida história de organização indígena na América Latina, algo fortalecido nos últimos anos pela crescente força do movimento indígena transnacional epelo financiamento eapoio de instituições mul- também sustenta que, nas regiões onde os afro-descendentes se mobilizaram politicamente como grupo, a reivindicação era pela igualdade, não pelo re conhecimento como um grupo distinto.

13. Ver, por exemplo, $\mathrm{H}$ anchard (1994) e W inant (1992, pp. 173-192).

14.Ver, por exemplo, M arx (1998) eN obles (2000).

15. Há, obviamente, umadimensão histórica na questão da identidade em torno da qual os grupos se organizam e do tipo dedemandaque realizam, dimensão relacionada, entreoutrosfa tores, aosincentivosproporcionados pelo Esta do. Isso é válido para os doisgrupos, naqualida dedepovosque, no pas sado, podem ter sido identificadoscomo camponeses ese organizado como tais, masquehoje se organizam em torno eem defesa daidentidade indígena e afro-descendente.

16. Van Cott (2000b, pp. 76-77), por exemplo, considera que os afro-colombianos não conseguiram conquistar osmermosdiretoscole 
tivosqueosgruposindígenas durante a Assembléia Constituinte de 1991 porque o movimento negro apresentavaum menornível deorganização e de politização em torno da identidadenegra. Em contraste, o movimento indíge na colombiano já estava organizado epôde, portanto, formular suas révindicações de forma a ecoar com os sentimentos relativosà crise dele gitimidade do Estado, crise que desencadeou a exigência de reformas constitucionais.

17. $\mathrm{Na}$ G uatemala, por exemplo, os garifuna conquistaram os mesmos direitos que os maya, poisforam incluídos na categoria grupo étnico/indígena, sem que houvesse da parte deles nenhuma reivindicação para tal inclusão. 0 sgarifuna são descendentes de escravos foragidos do Caribe e das Antilhas, e exilados naAmérica Central pe los ingleses no século XVIII. Há comunidades garifuna na costa caribenhada Guatemala, de Belize, de Honduras e da N icarágua.

18.Para análises da história da organização política afro-colombia tilaterais como o Banco Interamericano de Desenvolvimento, o Banco M undial e O N G sinternacionais (cf. Brysk, 2000). Certamente um movimento bem organizado e visível que possa se aproveitar das oportunidades políticas de mudança é um fator crucial na adoção de direitos coletivos na América Latina. M as a implementação de políticas multiculturais em países onde não havia movimentos indígenas ou afro-descendentes bem organizados ${ }^{17}$ sugere que, para compreender por que al guns grupos conquistaram direitos coletivos e outros não, é preciso levar em conta também as preferências das elites nacionais e da opinião pública.

A reivindicação desses direitos não assegura a satisfação das demandas pelo Estado. A questão da concepção é crucial para entender por que na Colômbia, por exemplo, os grupos indígenas foram mais bem-sucedidos do que os afro-descendentes. Segundo Van Cott (2000b, p. 76), a concepção usada para justificar os direitos col etivos dos negros na época da Assembléia N acional C onstituinte (AN C) "obteve pouca simpatia das elites políticas edos meios de comunicação". A orientação inicial do movimento negro, no sentido de uma política anti-racista que enfatizava a necessidade de combater a discriminação, e não no sentido de conquistar direitos coletivos especiais baseados na diferença cultural, não sensi bilizou as elites colombianas nem a opinião pública ${ }^{18}$. A capacidade do movimento indígena de formular a demanda por direitos coletivos de uma forma que se ajustasse às preocupações das elites e da opinião pública colombiana foi, assim, resultado não só de sua habilidade para capitalizar as novas oportunidades políticas, mas das preferências das elites e do público, preferências que legitimavam certas demandas e não outras. A pesar de o nível de organização dos movimentos dos dois grupos não ser irrelevante, a explicação que enfatiza esse fator não leva em conta a maior receptividade das elites e do público em relação a certos tipos de demanda.

Embora as explicações normal menteapresentadas para o discrepanteêxito dos dois grupos - tamanho relativo da população, falta de mobilização dosafro-descendentesem torno dos direitos coletivos, baixo nível deorganização do movimento negro - sejam relevantes, elasnão explicam por queem muitos países latino-americanos houve apoio político e da opinião pública para o "índio", entendido como umaidentidadequemereceria direitoscoletivos, e o mesmo não se deu em relação a uma identidade grupal "afro-descendente". Í ndio e negro são categorias raciais presentes nos sistemas (colonial e pós-independência) de classificação racial na América Latina, e o anti-racismo é parte do discurso político dos dois grupos, mas, ao contrário 
do que se dá com os grupos indígenas, nem todos os afro-descendentes podem formular reivindicações baseadas no caráter distintivo desua cultura. A Tabela 1 (p. 54) mostra como esses diferentes fatores se correlacionam (ou não) com o estabelecimento de direitos coletivos para os afro-descendentes. Embora osníveisdeidentidade degrupo eo grau deorganização não possam ser considerados irrelevantes, o fato de os negros serem ou não vistos como um grupo cultural distinto pareceser um fator crucial para entender por que conquistaram ou não direitos coletivos. A discrepância nas conquistas dos dois grupos não é, assim, resultado somente da diferença nos níveis de organização dos respectivos movimentos políticos, mas também conseqüência do fato de quea concessão detais direitos está baseada na posse de uma identidadecultural degrupo distinta, enão na história de exclusão política ou na discriminação racial.

Raça, etnia e direitos coletivos

O Estado e a opinião pública dos países latino-americanosforam, assim, mais sensíveisa demandas dos portadores da identidade indígena do que da afro-descendente, e às reivindicações formuladas em torno da diferença cultural ou etnicidade (indígena) do que às vinculadas a raça ou racismo (negritude) ${ }^{19}$. U m importante fator do êxito na conquista de direitos coletivos é, portanto, a habilidade dos grupos minoritários de formular demandas em termos adequados à lógica segundo a qual esses direitos são consideradosjustificados pelo regime de cidadania multicultural, lógica que implica a posse de uma identidade cultural distinta. Com base no trabal ho de pesquisadores como Edmund T. Gordon e Peter Wade, queanalisaram as diferentes maneiras pelas quais os Estados latino-americanos incorporaram (ou não) cidadãos indígenas ou afro-descendentes, sustento que as elites nacionais da região tendem a perceber osíndios como um grupo cultural distinto e que o mesmo não se dá em relação aos afro-descendentes. 0 escopo desigual dos direitos coletivos obtidos corresponde a certos pressupostos enraizados na região a respeito do tipo de sujeito racial e cidadão nacional constituído pelos afro-descendentes e pelos índios.

Em geral, os regimes de cidadania multicultural da América Latina na década de 1990 não foram adotados para resolver a ameaça política à estabilidadenacional representada por movimentosindígenas ou afro-descendentes $^{20}$. N a maioria dos casos, resultaram de decisões tomadas pelas elites nacionais no sentido de incrementar a legitimidade nacional-democrática na antes e depois da AN C, ver Restrepo (1997, pp. 279-319) e Wade (1993).

19. Para a ciência social eo senso comum, araça se referea diferençasfenotípicas entre grupos depessoas, ao passo que a etnia denota diferenças culturais. $N$ a maioriadoscasos, considerase que os afro-descendentescarecem de "etnicidade" eque, portanto, não mereceriam os direitos coletivos; é somentenoscasosem que raçaeetnicidadecoincidem que eles são capazes de reivindicar direitos coletivos.

20. Exceçõesa essatendênciasão aN icarágua, o M éxico ea Guatema la, ondeasinsurgências indígenas (e, no caso da $\mathrm{N}$ icarágua, revoltas indígenas e afro-descendentes, na década de 1980, contra o regime sandinista eque reivindicavam autodeterminação e outros direitos coletivos) levaram o Estado a tentar resolver politicamentetais conflitos, aceitando considerar (no M éxico e na Guatemala) ou implementar (na N icarágua) reformas de cidadania multicultural como parte dos acordos de paz. 
duranteo período detransição do autoritarismo. Segundo Van Cott, os regimes de cidadania multicultural são tentativas de remediar a exclusão passa$\mathrm{da}$, tentativas motivadas pela busca de diversas fontes delegitimidade para 0 Estado. A autora argumenta que, antes do atual período de transformação constitucional, aincapacidadedos governoslatino-americanos deaprimorar o bem-estar material deseus cidadãose deassegurar aigual dadeperantea lei gerou uma crise delegitimidade do Estado. Assim, promovendo o multiculturalismo, "os políticos que elaboraram as constituições latino-americanas apostaram que a diversidade étnica poderia [...] promover a unidade nacional ao chamar a atenção para o problema da exclusão política, ao enfatizar a importância dos direitos democráticos eao introduzir na cultura política os valores de partici pação, inclusão etolerância" (Van Cott, 2000b, p. 278).

Apesar de o objetivo declarado das reformas de cidadania multicultural ser 0 aprimoramento da legitimidade democrática mediante a reversão da exclusão social de minorias étnicas eraciais, nem todos esses grupos se beneficiaram dedireitos coletivos. 0 critério para a concessão de tais direitosnão foi, por exemplo, a discriminação racial sofrida pelos grupos, mas se eles eram considerados ou podiam melhorar seu status como um grupo cultural distinto no interior da sociedade mais ampla. Com isso, o modelo multicultural latino-americano se revelou mais compatível com demandas baseadas na diferença cultural ou na identidade "étnica" do quena diferençaracial. 0 que precisa ser explicado para compreendermos a discrepância nos direitos coletivos conquistados pelos dois grupos não é, assim, por que os afro-descendentes não se mobilizaram, mas quais condições facilitaram a maior politização da etnicidade do que da raça.

Se os movimentos indígenas foram mais bem-sucedidos no modo como formularam suas reivindicações, isso se deve, em parte, a certos atributos queo imaginário nacional associa ao povo eà cultura indígena (mas não aos afro-descendentes). Como Edmund Gordon apontou em relação à N icarágua, "há vários tipos de racismo contra o metizo" ediferem os modos pelos quais os índios e os negros são representados como marginais e inferiores (cf. Gordon, 1998, p. 121). Wade sugerealgo similar para a América Latina como um todo ao afirmar que "negros eíndios foram caracterizados como 00 utro, localizados em espaços liminares da nação, mas foram inseridos de forma distinta no que chamo de estruturas de alteridade" (Wade, 1997, p. 36). N a mai oria dos casos, as ideologias nacionais latino-americanas consideram a nação o produto de um processo de mistura que teria envolvido exclusivamente homens espanhóis e mulheres índias, resultando em uma 
cultura predominantemente espanhola com al gumas contribuições indígenas. $N$ esses casos, os povos indígenas ocupam certo lugar no universo simbólico da nação, já que teriam dado uma contribuição ancestral à nova nação e à cultura híbrida, ainda que hoje sejam considerados marginais e tradicionais. A ideologia do indigenismo, que retrata o índio como símbolo paradigmático da identidade nacional em países como M éxico ePeru, também facilitou a percepção desse povo como um grupo distinto digno de reconhecimento ${ }^{21}$. $0 \mathrm{~s}$ afro-descendentes, em contraste, permaneceram invisíveis em grande parte das narrativas nacionais de mestizaje latino-americanas e, portanto, seu lugar na comunidade política nacional é mais ambíguo. M esmo nos casos em que são reconhecidas as raízes culturais africanas da cultura nacional, como no Brasil e em Cuba, é difícil sustentar a especificidade da cultura negra quando ela é identificada à cultura nacional.

O safro-descendentes estão assim em desvantagem em relação aosgrupos indígenas para reivindicar direitos coletivos, já que o modo diferente pelo qual os dois grupos foram historicamente racializados afeta as respectivas capacidades para afirmar uma identidade cultural de grupo distinta. $\mathrm{N}$ em todos os afro-descendentes se consideram um grupo étnico ou são percebidos pelas elites nacionais e a opinião pública como possuidores de uma "identidade étnica" que mereceria ser protegida por direitos coletivos especiais. Wade aponta quena Colômbia, por exemplo, osnegros não são considerados um grupo distinto na mesma medida dosíndios, já que, ao contrário destes, adotaram, graças à aculturação, a cultural nacional mestiça. Os afro-colombianos, sustenta Waden, "são vistos muito mais como cidadãos (desegunda classe), estudadosem relação aosnão-negrosem uma'sociedade de classe' e que não teriam uma 'cultura negra'". Em contraste, prossegue ele, parte da identidade dos índios, "atribuída ou reivindicada, consiste na linguagem e na cultura distintas" (Wade, 1997, pp. 21, 85, 36). 0 esboço feito por Waden das posições dos afro-descendentes e dosíndios colombianos na ordem racial nacional ilustra a paradoxal situação dos primeiros em relação às reformas. Por um lado, na qualidade de grupo que sofre exclusão política e discriminação racial, a inclusão dos afro-descendentes poderia conferir maior legitimidadedemocrática ao Estado. Por outro, como não são considerados um grupo distinto (já que sua diferença seria apenas racial e não étnica ou cultural), eles não mereceriam os mesmos direitos coletivos concedidosaosíndios.

D urante os debates na AN C colombiana, por exemplo, o maior êxito dos grupos indígenas na apresentação de demandas em uma forma que
21. É importantenotar, porém, que o apelo re tórico às raízes indígenas da cultura nacional não significa incluir os índios ou respeitar seus direitos como cidadãos. Sobre o indigenismo no M éxico, ver Knight (1990, pp. 71-113). 
22. Três delegados índios participaram da ANC e nenhum afrocolombiano. Foram os delegados índios que apresentaram as reivindicações dos afro-coIombianos na ANC.

23. $\mathrm{N}$ aN icaráguacriollo emulato não são sinônimos. O scriollossão descendentes de espanhóis nascidos nas A méricas. O smulatos são descendentes de escravos africanos foragidos e de escravostrazidospelosingleses para a Costa do M osquito durante o sé culo XVI; eles falam a línguainglesaesetornaram cada vez mais dominantes na Costa do M osquito duranteossé culosXVIII eXIX. estava em consonância com a opinião pública e os meios de comunicação não se deveu apenas à maior visibilidade desses grupos²2. Ele resultou também da percepção, por parte da opinião pública e das elites políticas, dos índios como cidadãos específicosquemereceriam direitos coletivos. N a AC N argumentou-se explicitamente que os afro-colombianos não mereciam direitos coletivos porque não constituíam um "grupo étnico" com linguagem e tradição próprias (cf. Grueso, Rosero e Escobar, 1998, p. 199). Q uando incluíam os afro-colombianos na categoria de "grupo étnico", as propostas iniciais submetidasà AN C procuravam distinguir entre "povosindígenas" e grupos étnicos, distinção baseada no pressuposto de que mai oria dos afrocolombianos (com exceção dos habitantes tradicionais das il has caribenhas) não teria uma etnicidadee, portanto, não mereceria direitos coletivos, espe cialmente os culturais (cf. Rodriguez, 1992, p. 46).

Vale notar, porém, que após a AN C uma identidade afro-colombiana entendida de forma explicitamente "étnica" foi criada, politizada e disseminada por certas organizações negras. A construção dessai dentidade, queprivilegia antesa diferença cultural eétnica do quea discriminação racial, como fundamento de projetos políticos negros na década de 1990, foi elaborada mediantea apropriação parcial do tipo de formulação que osíndios deram à reivindicação de direitos coletivos (cf. Restrepo, 1997, pp. 295-301; Wade, 1995, pp. 342-358). A reformulação da identidadeafro-colombiana em termos culturais ea relutância das el ites políticas desse país em aceitar osnegros como um grupo culturalmente distinto na época da AN C indicam bem o modo pelo qual os gruposindígenasforam vistos como sujeitos "adequados" decertos direitos coletivos (como autonomia política, propriedadecomunal da terra e preservação da cultura tradicional), principalmente em razão de sua diferença cultural e dos supostos conteúdos dessa cultura.

M asnão se trata apenas da existência de uma cultura distinta. A questão envolveainda a posse de um tipo particular decultura ou etnicidade. G ordon aponta que na $\mathrm{N}$ icarágua o discurso nacional retratava os índios como atrasados, primitivos e carentes de civilização, ao passo que os negros mulatos ${ }^{23}$ eram considerados desprovidos de cultura, inferiores e, em razão de sua origem estrangeira, ilegítimos. O s negros não são vistos como portadores de uma cultura "tradicional" ou ancestral. Assim, com a introdução das reformas de cidadania multicultural, o que mudou não foi, necessariamente, os atributos associados ao povo indígena, mas o valor dado a eles: hoje, a posse de uma cultura ancestral não é mais marca de "atraso", mas de possibilidade de preservar essa cultura por meio de direitos coletivos espe- 
ciais. I sso é particularmente verdade para aquelas culturas que, segundo se afirma, teriam dado contribuições cruciais para a identidade nacional mestiça contemporânea. 0 s movimentos indígenas da América Latina adaptaram suas estratégias a essas novas condições e, em vez de reivindicar direitos coletivos em nome de uma minoria oprimida, invocaram sua identidade como "povo" distinto com direito aos territórios que habitavam antes da chegada dos colonizadores. Em al guns países, essa mudança pode ser notada na substituição do termo "indígenas" por "pueblos".

A importância da afirmação de uma identidade étnica para a conquista de direitos coletivos éilustrada pelo fato de que os países em que as comunidades de afro-descendentes obtiveram reconhecimento como grupos distintos e direitos coletivos foram, em geral, aqueles onde elas conseguiram reivindicar uma posição autóctone, similar à dos índios. Em vários países da América $\mathrm{C}$ entral (H onduras, $\mathrm{N}$ icarágua e Guatemala), os grupos afrodescendentes foram reconhecidos como uma população distinta com diferenças culturais em relação à nação e seus direitos coletivos foram inseridos no quadro legal econstitucional. Creolese garifuna de H onduras; na G uatemala e na $\mathrm{N}$ icarágua, por exemplo, ocupam uma posição autóctone semeIhanteà dosíndios. Esse status "aborígine" ébaseado na linguagem e cultura distintas, presença anterior à formação do Estado nacional, associação histórica com grupos indígenas durante o M osquito Kingdom and Reserve no caso dos creoles da N icarágua e intercasamento com populações indíge nas no caso dos garifuna. 0 acordo presidencial assinado em 1994, que reconheceu $\mathrm{H}$ onduras como um país multiétnico e multicultural, e instituiu a educação bilíngüe e intercultural para os "grupos étnicos autóctones", incluiu os garifuna e os creoles de língua inglesa na definição de etnias autóctones. $\mathrm{N}$ a Guatemala, da mesma forma, os garifuna foram incluídosna definição de grupos indígenas. A esse respeito, $M$ ark Anderson sustenta que "a capacidade das organizações garifuna de reivindicar um statussimilar ao dosindígenas foi fundamental para seu êxito na obtenção de direitose de certo grau de reconhecimento do Estado hondurenho na década de 1990, e ainda é um fator importante nas lutas travadas" (2003, p. 3). Como a discussão anterior do caso colombiano mostrou, a questão da posse ou não, por parte dos afro-colombianos, de uma identidade étnica foi central no debate que decidiu se eles mereciam ou não direitos coletivos. $N$ os outros casos em que os afro-descendentes conquistaram al guns direitos, como no Brasil eno Equador, esses grupos foram incorporados não à categoria afrodescendente como um todo, mas à de comunidades negras rurais, que ocu- 
24.Yashar (1999, p. 104, n. 4), por exemplo, faz uma distinção entre a clivagem étnica e a racial, e aponta que está interessada na politização da primeira e não da segunda. pam uma posição similar à dosíndios, já que são vistas como grupos culturalmente distintos.

É assim problemática a distinção nítida entre política racial e étnica pressuposta em muitos estudos que enfatizam apenas os movimentos indígenas. Esses estudos presumem que os afro-descendentes podem ser excluídos da análise da política étnica na América Latina porque constituiriam um grupo racial enquanto os índios formariam um grupo étnico ${ }^{24}$. A distinção nítida entre raça e etnicidade desconsidera o fato de que, historicamente, "indígena" funcionou como uma categoria racial na América Latina (cf. Wade, 1997, p. 37). D esconsidera ainda o fato de que as definições de raça e etnia podem se sobrepor, já que várias identificações raciais podem coexistir no interior do mesmo grupo étnico e vice-versa. 0 que está sendo pressuposto é que os afro-descendentes se vêem como sujeitos raciais e não reivindicam a posse de identidade "étnica" ou direitos coletivos com base nesta.

Dessa forma, a maioria das explicações para o menor êxito dos afrodescendentes em comparação aos índios na conquista de direitos coletivos tende a enfatizar as supostas diferenças entre os dois grupos, sem analisar 0 papel do Estado na criação da disparidade. N egligencia-se, assim, o fato de que as instituições estatais e as preferências das el ites nacionais e da opinião pública desempenham um papel na determinação da capacidade dos grupos de conquistar direitos coletivos. N osso argumento, em contraste, éque os grupos indígenas foram mais bem-sucedidos nessa luta porque é mais fácil para eles formular suas reivindicações dentro dos parâmetros segundo os quais os direitos coletivos foram assegurados na América Latina, e essa capacidade diferencial está vinculada ao modo como os grupos foram racializados em toda a região. Em suma, os grupos indígenas conquistaram mais direitos coletivos do que os afro-descendentes em parte porque os novos regimes de cidadania multicultural da região são mais sensíveis a demandas formuladas com base na diferença cultural ou na identidade étnica do que na discriminação ou diferença racial, e essa forma de justificar os direitos coletivos determinou o maior êxito dosíndios.

Políticas afro-descendente e indígena no modelo multicultural

Q uais as conseqüências da disparidade de êxito entre os grupos? Q ual a relevância do fato de que os indígenas estão mais bem posicionados do que os afro-descendentes para formular reivindicações baseadas na diferença 
cultural? Constituiria um problema o fato de apenas um pequeno subconjunto da população afro-descendente da região poder reivindicar direitos coletivos? $0 \mathrm{~s}$ afro-descendentes devem aspirar direitos coletivos baseados na diferença cultural? Em suma, quais as implicações, para as políticas dos dois grupos, de os direitos coletivos serem adjudicados principalmente segundo a diferença cultural, beneficiando, assim, mais os grupos indígenas? A literatura sobre a reforma de cidadania multicultural tendeu a enfatizar 0 modo como os direitos coletivos para ambos os grupos expandiram as concepções de cidadania existentes na América Latina, graças à rejeição de noções caras à democracia liberal, como por exemplo a visão de que igualdade significa que todos os cidadãos devem ter os mesmos direitos ou de que 0 indivíduo é o único portador de direitos. Ao mesmo tempo, porém, éimportantenão ser muito otimista quanto à possibilidade deas reformas reverterem a exclusão política e a discriminação racial sofrida pelos dois grupos, especialmente em razão da disparidade do acesso a tais direitos.

As reformas de cidadania multicultural na América Latina privilegiam certos agentes e modos de formular as reivindicações que encerram potenciais conseqüências negativas. A necessidade de afirmar uma identidade étnica ou cultural distinta significa que não só a mai oria dos afro-descendentes, mas também al guns grupos indígenas não poderão conquistar direitos coletivos ${ }^{25}$. Assim, os afro-descendentes que não conseguem afirmar uma identidade "étnica" carecem deuma base parareivindicar os direitos, mesmo que também sofram exclusão política e discriminação racial. Aqueles que puderam afirmar uma posição semelhante à dosíndios conquistaram direitos coletivos. M as, seamaioria daspopulaçõesnegras daAmérica Latinaéde fato urbana e não se distingue etnicamente da cultura mestiça mais ampla, então ela estará em desvantagem na luta pelos direitos coletivos, pelo menos enquanto estes forem concebidos em termos de diferença cultural. Além disso, o emprego desse critério para avaliar quem serão os beneficiários dos direitos coletivoséproblemático também em relação aosíndios ${ }^{26}$. N os debates constitucionais realizados em 1997 na N icarágua, por exemplo, a respeito das reformas multiculturais, a tentativa de estender os direitos coletivosa grupos indígenas que estão além da costa atlântica foi derrotada pelos argumentos de que essas populações não possuíam mais uma identidade étnica distinta, já que se teriam tornado um agrupamento camponês mestiço aculturado ${ }^{27}$. A disparidadeno acesso a di reitos coletivos pode gerar divisões entreos que conseguem eosquenão conseguem conquistá-los, tanto no interior como entre as comunidadesafro-descendentes eas indígenas.
25. Certo número de comunidades empenhou-se em processos de "re-indianização", possivelmente em respostaataisimperativos. Ver, por exemplo, Speed, (2002, pp. 205228).

26. Os povos indígenas que não mais possuem os traços associados à diferença cultural, como linguagem, ritual ou roupas tradicionais, e que vivem em áreas urbanas também podem ser excluídos das políticasmulticulturais. Ver Ramos (2000).

27. Para uma análise de como as diferentes narrativas sobre mestiçagem afetaram os debates sobre direitos coletivosna $\mathrm{N}$ icarágua durante a década de 1980, ver Hooker (2005, pp. 14-39). 
28. Essa crítica das políticas de reconhecimento baseadasapenas na diferença cultural foi formulada em debates sobre política de identidade realizados nos Estados Unidos e em outros países. Ver Fraser (1997).
O utro perigo, talvez maisimportante, équea necessidadedeformular as demandas com base na diferença cultural pode levar os grupos afro-descendentes e indígenas a privilegiar, para efeitos de mobilização política, o tema do reconhecimento cultural, e não o da luta contra a discriminação racial. Em relação a H onduras, por exemplo, $\mathrm{M}$ ark Anderson apontou que, para ganhar direitos do Estado, osgarifuna elaboraram um discurso similar ao do movimento indígena, enfatizando a existência de um tipo particular de sujei to coletivo merecedor dedireitos. D essa forma, o discurso anti-racista, até então predominante na política dos garifuna, subordinou-se à linguagem dos direitos indígenas (cf. Anderson, 2003, p. 24). I sso não implica sugerir que osíndiosnão empregam também um discurso anti-racista; aponto ape nas que, quando os afro-descendentes enfatizaram a diferença cultural na tentativa de obter direitos coletivos, isso se deu em detrimento de um discurso contra a discriminação racial ea exclusão social e econômica. N o caso dos afro-colombianos, por exemplo, a mobilização que acompanhou a AN C apresentou uma mudança no discurso político negro: a ênfase na discriminação racial e na necessidade de reverter a exclusão social deu lugar a uma política de diferença cultural, que insistia nas raízes culturais africanas daidentidade afro-colombiana eno vínculo histórico da comunidadenegra com certos territórios (cf. Restrepo, 1997). Como Anderson apontou em relação a H onduras, os afro-descendentes não teriam conquistado direitos coletivossetivessem sebaseado apenasna política anti-racista, poiso Estado hondurenho (como o colombiano e a maioria dos Estados latino-americanos) ainda reluta em aceitar a existência do racismo. N esse sentido, o reconhecimento da diversidade cultural, iniciativa que não necessariamente enfrenta os aspectos sociais e econômicos da injustiça racial, permite que os Estados continuem ignorando a existência do racismo ${ }^{28}$.

0 privilégio concedido ao reconhecimento cultural no modelo multicultural apresenta problemas para os afro-descendentes e os índios, já que os direitos culturais podem não dar conta das desvantagens reais enfrentadas pelas duas populações, especialmente quando, no interior de um mesmo grupo, há múltiplos e sobrepostos tipos de identidade coletiva, resultando em várias formas de desvantagem que, evidentemente, exigem diferentes estratégias de enfrentamento. C onsidere o exemplo da discriminação racial contra índios e afro-descendentes que se manifesta em formas que não a desvalorização de suas culturas: para enfrentar tais injustiças é preciso, além das políticas de reconhecimento cultural adotadas nas duas últimas décadas, a implementação de uma "abordagem forte de direitos 
civis'29. 0 tema começa a ser enfrentado em al guns países. No Brasil, por exemplo, medidas de ação afirmativa para cargos públicos e educação superior foram recentemente introduzidas ao lado da legislação existente que protege os direitos comunais relativos à terra dos povos indígenas e dos quilombos afro-descendentes. D a mesma forma, em 1996 a C orte C onstitucional Colombiana ampliou o escopo dos direitos coletivos para além das pequenas populações raizais e ribeirinhas da costa do Pacífico, argumentando que, embora nem todos os afro-colombianos satisfaçam os critérios da definição restrita de comunidade negra como uma cultura tradicional ribeirinha, eles merecem tais direitos por serem vítimas de "marginalização social" (cf. Van Cott, 2000a, p. 50).

O s casos do Brasil e da Colômbia sugerem como enfrentar no futuro a exclusão da maioria dos afro-descendentes que não pôde conquistar, com base na diferença cultural, direitos coletivos. A adoção simultânea de direitos culturais e outros tipos de estratégias anti-racistas, como a ação afirmativa ou medidas relacionadas aos direitos civis, ainda é uma exceção na América Latina. D eve-se notar, porém, que o problema não se reduz ao fato de que os direitos culturais estão se tornando o principal meio pelo qual os Estados latino-americanos tentam resolver a questão da injustiça e da desigualdade: os próprios movimentos indígenas e afro-descendentes tendem a priorizar, em suas lutas, certos direitos em detrimento de outros. É crucial que as lutas dos dois movimentos sejam estudadas simultaneamente, pois tais questões só podem ser ressal tadas por uma análise conjunta. A inclusão dos afro-descendentes na análise das reformas de cidadania multicultural na América Latina é fértil porque a luta dessa população, situada na ambígua intersecção de raça e etnicidade, não pode ser facilmente enquadrada na categoria "reconhecimento cultural". Além de preencher uma lacuna na literatura relativa à política afro-descendente no contexto das reformas de cidadania multicultural, esteartigo sugere certas limitações e possibilidades do novo modelo multicultural latino-americano. A análise feita aqui tem implicações para a política do movimento indígena e do afro-descendente, ao apontar que o maior êxito do primeiro na conquista de direitos coletivos e a tentativa do segundo de imitar essa estratégia bem-sucedida encerram certo custo: a primazia da política de reconhecimento cultural em detrimento da política anti-racista. $M$ as também se vislumbram aqui certas possibilidades, pois os índios e os afro-descendentes latino-americanos sofrem os dois tipos de injustiça e podem, assim, promover simultaneamente as duas políticas, sem que seja necessário dar prioridade a uma delas.
29.É essa a conclusão alcançada por Cottrol e H ernandéz (s.d., pp. 14-15). 
TABELA 1

Explicando a disparidade na conquista de direitos coletivos pel os grupos indígenas e afro-descendentes

\begin{tabular}{|c|c|c|c|c|c|}
\hline País & $\begin{array}{l}\text { POPULAÇÃO AFRO-DES- } \\
\text { CENDENTE MENOR DO } \\
\text { QUE A IN DÍGENA }\end{array}$ & $\begin{array}{l}\text { M OVIMENTO AFRO-DES- } \\
\text { CENDENTE MAISORGANI- } \\
\text { ZADO }\end{array}$ & $\begin{array}{l}\text { ALtO GRAU DE IDENTI- } \\
\text { DADE DE GRUPO AFRO- } \\
\text { DESCENDENTE }\end{array}$ & $\begin{array}{l}\text { (ALGUNS) AFRO-DES- } \\
\text { CENDENTES SÃO VISTOS } \\
\text { COMO UM GRUPO CULTU- } \\
\text { RAL DISTINTO }\end{array}$ & $\begin{array}{l}\text { (ALGUNS) DIREITOS COLE- } \\
\text { VOSAFRO-DESCEN DENTES }\end{array}$ \\
\hline BRASIL & N ão & Sim & N ão & Sim & Sim \\
\hline COSTA RICA & $\mathrm{Sim}$ & $\mathrm{N}$ ão & N ão & N ão & N ão \\
\hline Colômbia & N ão & N ão (em 1991) & N ão (em 1991) & Sim** & Sim \\
\hline EQUADOR & Sim & Igual & N ão & Sim & Sim \\
\hline Guatem ala & Sim & N ão & N ão & Sim & Sim \\
\hline HONDURAS & N ão & Igual & Sim & Sim & Sim \\
\hline Méxıco & Sim & $\mathrm{N}$ ão & N ão & N ão & N ão \\
\hline NICARÁGUA & Sim & N ão & Sim & Sim & Sim \\
\hline Panamá & N ão & N ão & N ão & N ão & N ão \\
\hline Peru & Sim & N ão & Sim & N ão & N ão \\
\hline VENEZUELA & N ão & $\mathrm{N}$ ão & N ão & $\mathrm{N}$ ão & $\mathrm{N}$ ão \\
\hline
\end{tabular}

* A classificação em sim/não das complexas situações dos vários países incluídos nesta tabela implica, obviamente, certa simplificação, e al gumas marcações poderão ser contestadas pelos especialistas de cada nação. 0 objetivo aqui é apenas mostrar que, entre todos os fatores que podem explicar a discrepância nos direitos coletivos dos grupos indígenas eafro-descendentes na América Latina atual, a capacidade de reivindicar uma identidade de grupo cultural distinto parece ser altamenterelevante.

** Costa do Pacífico (população ribeirinha) e população raizal.

\section{Referências Bibliográficas}

Anderson, M ark. (2003), "W hy black politics (sometimes) looks like indigenous politics in Latin America: insights from Garifuna Movements in Honduras". Trabalho apresentado no Seminário Rockefeller sobre Direitos Raciais e Recursos nas Américas. Austin, Texas, Universidade do Texas, 21 de março.

ArIAs, 0 mar \& D URYEA, Suzzane. (s.d.), "Social exclusion due to race or ethnicity in Latin America: what do we know". Working Paper, Inter-American D evelopment Bank.

BRYSK, Alison. (2000), From tribal villageto global village: indian rightsand international relations in Latin America. Stanford, Stanford University Press.

BrysK, Alison \& W WSE, Carol. (1997), "Liberalization and ethnic conflit in Latin America". Studies in Comparative International D evelopment, 32 (2): 76-105.

Cottrol, Robert J. \& Hernández, Tanya Kateri. (s.d.), "The role of law and legal institutions in combating social exclusion in Latin American countries: afro- 
american populations". Working Paper, Inter-American D evelopment Bank, pp. 14-15.

Fraser, N ancy. (1997), Justice interruptus: critical reflections on the "postsocialist" condition. N ova York, Routledge.

GoRdon, Edmund T. (1998), Disparate diasporas: identity and politics in an African Nicaraguan community. Austin, U niversity of Texas Press, p. 121.

Grueso, Líbia; Rosero, Carlos \& Escobar, Arturo. (1998), "The process of black community organizing in the Southern Pacific Coast Region of Colombia". In: Alvarez, SoniaE.; Dagnino, Evelina \& Escobar, Arturo (eds.), Cultures of politics/ politics of cultures: revisioning Latin American social movements. Boulder, CO, Westview Press.

H ALE, C harles. (2002), "D oes multiculturalism menace? G overnance, cultural rights and the politics of identity in Guatemala". Journal of Latin American Studies, 34 (3): 485-524.

H ANCHARD, M ichael. (1994), Orpheus and power: the Movimento N egro of Rio de Janeiro and São Paulo, Brazil, 1945-1988. Princeton, Princeton University Press. H OOKER, Juliet. (2005), “'Beloved enemies': race and official mestizo nationalism in N icaragua". Latin American Research Review, 40 (3): 14-39.

H openhayn, M artín \& Bello, Alvaro. (2001), “Discriminación étnico racial y xenofobia en América Latina y el Caribe". D ivisión de D esarrollo Social de la Comisión de las N aciones Unidas para América Latina (Cepal/Eclac), Santiago, Chile, p. 5. KNight, Alan. (1990), "Racism, revolution and indigenismo: M exico, 1919-1940". In: GraH AM, Richard (ed.), Theidea of race in Latin America, 1870-1940. Austin, University of Texas Press, pp. 71-113.

LovelL, Peggy. (1994), "Race, gender and development in Brazil". Latin American Research Review, 29 (3): 7-35.

M ARX, Anthony. (1998), M aking race and nation: a comparison of the U nited States, South Africa, and Brazil. Cambridge, Cambridge University Press.

N obles, M elissa. (2000), Shades of citizenship, race and the census in modern politics. Stanford, Stanford University Press.

O AKLey, Peter. (2001), "Social exclusion and Afro-Latinos". Working Paper, InterAmerican Development Bank.

Patrin Os, H arry Anthony. (2000), "The cost of discrimination in Latin America". Studies in Comparative International D evelopment, 35 (2): 4, verão.

Ram os, Alcida. (2000), The commodification of the Indian. Brasilia, Universidade de Brasília.

Restrepo, Eduardo. (1997), “Afro-colombianos, antropología y proyecto de modernidad en Colombia". In: U RIBE, M aria Victoria \& Restrepo, Eduardo (eds.), 
Antropología en la modernidad: identidades, etnicidades y movimientos sociales en Colombia. Bogotá, Colômbia, Instituto Colombiano deAntropología, pp. 279-319. Rodríguez, Jaime Arocha. (1992), "Afro-Colombia denied". N ACLA Report on the Americas, 35 (4): 46.

SiLva, N elson do Valle. (2000), "A research note on the cost of not being white in Brazil". Studies in Comparative International D evelopment, 35 (2):18-28, verão. Speed, Shannon. (2002), "Global discourses on the local terrain: human rights and indigenous identity in Chiapas". Cultural Dynamics, 14 (2): 205-228.

Thorne, Eva. (2003), "The politics of Afro-Latin land rights". Trabalho apresentado no 34th annual meeting of the N ational C onference of Black Political Scientists, 0 akland, CA, p. 5, 12-13 de março.

V An Cott, D onna Lee. (2000a), "Latin America: constitutional reform and ethnic right". Parliamentary Affairs, 53 (1): 41-54.

. (2000b), The friendly liquidation of the past: the politics of diversity in Latin America. Pittsburgh, University of Pittsburgh Press.

W ADE, Peter. (1993), Blackness and race mixture: the dynamics of racial identity in Colombia. Baltimore, Johns H opkins U niversity Press. . (1995), "T he cultural politics of blackness in Colombia". American Ethnologist,

22 (2): 342-358. . (1997), Race and ethnicity in Latin America. Londres, Pluto Press.

W INANT, H oward. (1992), "Rethinking race in Brazil". Journal of Latin American Studies, 24: 173-192.

YASH AR, D eborah. (1999), "D emocracy, indigenous movements, and the postliberal challenge in Latin America". World Politics, 52 (1): 76-104.

\section{Resumo}

Inclusão indígena e exclusão dos afro-descendentes na América Latina

Este artigo analisa as causas da disparidade nos direitos coletivos conquistados por grupos afro-latinos durante as recentes iniciativas de reformas relacionadas à cidadania multicultural na América Latina. Em vez de atribuir o maior êxito dos índios na conquista desses direitos a diferenças no tamanho da população e a níveis mais elevados de identidade de grupo ou de organização dos movimentos indígenas, a autora sustenta que a principal causa da disparidade está no fato de os direitos serem atribuídos levando em conta uma identidade de grupo distinta, definida por meio de critérios étnicos ou culturais. O s índios estão, em geral, melhor posicionados do que a maioria dos afro-latinos para reivindicar uma identidade de grupo étnico, distinta da cultural nacional, e por isso foram mais bem-sucedidos na conquista dos direitos coletivos. A autora sugere ainda que uma das conseqüências potencialmente negati- 
vas da vinculação dos direitos coletivos à diferença cultural é que isso pode levar os grupos indígenas e afro-latinos a privilegiar, como fundamento para a mobilização política, temas relacionados ao reconhecimento cultural, em detrimento dos temas centrados na discriminação racial.

Palavras-chave: M ulticulturalismo; América Latina; N egros; Povos indígenas.

\section{Abstract}

Indiginousinclusion and afro-descendant exclusion in Latin America

The author analyses the causes of the disparity in collective rights gained by indigenous and Afro-Latin groups in recent rounds of multicultural citizenship reform in Latin America. Instead of attributing the greater success of indians in winning collective rights to differences in population size, higher levels of indigenous group identity or higher levels of organisation of the indigenous movement, it is argued that the main cause of the disparity is the fact that collective rights are granted on the basis of possessing a distinct group identity defined in cultural or ethnic terms. Indians are generally better positioned than most Afro-Latinos to claim ethnic group identities separate from the national culture and have therefore been more successful in winning collective rights. $O$ ne of the potentially negative consequences of basing group rights on the assertion of cultural difference is that it might lead indigenous groups and Afro-Latinos to privilege issues of cultural recognition over questions of racial discrimination as bases for political mobilisation in the era of multicultural politics.

Keywords: M ulticulturalism; Latin America; Blacks; Indigenous people.
Juliet H ooker éprofessora assistente no Departamento de G overno daUniversidade do Texas, em Austin, Estados Unidos. O bteve o PhD na Cornell University em 2001. E-mail: juliethooker@ mail.utexas.edu. 